\title{
An Analysis of Minor Hysteresis Loops Behavior under PWM Voltage - Electromagnetic Device at No-Load and Loaded Conditions
}

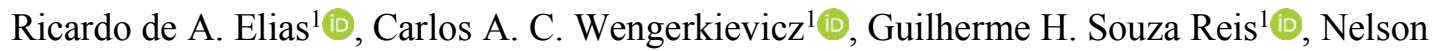 \\ Sadowski ${ }^{1}$, Nelson J. Batistela ${ }^{1}$, João Pedro A. Bastos ${ }^{2}$, \\ ${ }^{1}$ GRUCAD/EEL/UFSC, P.O. Box 476, 88040-970, Florianópolis, Santa Catarina, Brazil, \\ ricardo.elias@posgrad.ufsc.br,c.a.correa@posgrad.ufsc.br,nelson.sadowski@ufsc.br,jhoe.batistela@ufsc.br \\ ${ }^{2}$ PPGSE/UFSC, 8300 Dona Francisca St., CEP: 89.219-600, Joinville, Santa Catarina, Brazil, \\ assumpcao.bastos@ufsc.br
}

\begin{abstract}
This paper addresses the influence of the primary and secondary resistances on the behavior of minor hysteresis loops when the electromagnetic device is fed by three-level PWM (pulse width modulation) voltage. To study the device transferring energy to a load, the experimental approaches are different of traditional procedures to material characterization, where problems inherent to the process are added. Analytical, FEM and experimental analysis are performed on a toroidal transformer equipped with a flux sensing coil. The leakage fluxes related to the primary and secondary currents are shown to cause errors in the measurement of the core magnetization current. A solution to mitigate this problem is employed, consisting in twisting and winding together primary and secondary conductors. Experimental methodologies for obtaining the value of the iron losses when the device is transferring energy to a load are also performed. The study showed that supply voltage with three-level PWM waveform causes minor hysteresis loops and the greater the resistance value of the excitation winding, the larger the areas of the minor hysteresis loops. On the other hand, by increasing the energy transferring to a load the minor loops areas tend to decrease.
\end{abstract}

Index Terms - electromagnetic device with load, finite element method, leakage flux, magnetic losses, PWM regime, time constant.

\section{INTRODUCTION}

The study on magnetic losses (losses in ferromagnetic cores) is a current issue addressed for academic, environmental, commercial and energy efficiency motivations. For instance, in three-phase induction motors supplied by sinusoidal sources, core losses correspond to about $15 \%$ to $25 \%$ of total losses [1]. In experimental studies carried out in [2], these losses increased between $150 \%$ and $400 \%$ when the motor was supplied by a frequency converter. Generally, studies and measurements of losses in ferromagnetic materials are performed for the condition where there is no transfer of energy to a load, as in [2]. Few studies have investigated the influence of the load on the behavior of magnetic losses under PWM (pulse width modulation) supply regime, as [3]-[6]. Zhang et al. [4] used 
Journal of Microwaves, Optoelectronics and Electromagnetic Applications, Vol. 20, No. 4, December 2021

DOI: http://dx.doi.org/10.1590/2179-10742021v20i4254768

the finite element method to calculate the magnetic losses for two motors (5.5 kW and $30 \mathrm{~kW})$ operating with and without load, with sinusoidal and PWM supply, and compared them with experimental values. By changing the supply from sinusoidal to PWM, the calculated total magnetic losses increased $37 \%$ and $19 \%$ for the $5.5 \mathrm{~kW}$ and $30 \mathrm{~kW}$ motors, respectively. In [3], the effect of the converter switching frequency on the magnetic losses and its measurement methods are studied in a toroidal sample. This work will be covered in detail later. In [6], the core losses of an induction motor were evaluated for different materials while supplied by the electrical grid or by a PWM source. Experimental results of three motors are presented, as well as results from analytical modeling and from finite element method (FEM) simulations. Although the methodologies used in the comparison of the studied cases are not so clear, it is concluded in [6] that the core losses increase with the increase of the mechanical load. In [5] is presented an analyses based on FEM simulations and experimental tests, concluding that there is an increase in the core losses of a permanent magnet motor when supplied with PWM voltage and with mechanical load.

The present work presents an investigation with its own methodology and a proposal for the evaluation of hysteresis losses in electromagnetic devices when operating in pulsed regimes and connected to a load. A transformer with three windings and toroidal core is used in the study. The use of a toroid as magnetic circuit for the characterization of ferromagnetic materials has peculiarities such as the advantage of knowing the average magnetic path and the disadvantage of not being possible to compensate the leakage flux. This disadvantage is assessed through FEM simulations and experiments. The development of tests and issues associated with the characterization of the magnetic device are presented. This device, with three windings and a toroidal core, enables the energy transfer from the power source to the load, simultaneously allowing the determination of the magnetization loop of the core material through measurements of magnetic flux and magnetization field.

\section{SYSTEM WITH THREE-WINDING TRANSFORMER}

The electromagnetic circuit adopted to perform the study consists of a transformer with a toroidal core and three windings. Figure 1 presents a simplified block diagram of the magnetic circuit, its power supply, the load and a closed-loop scheme that was used in some tests.

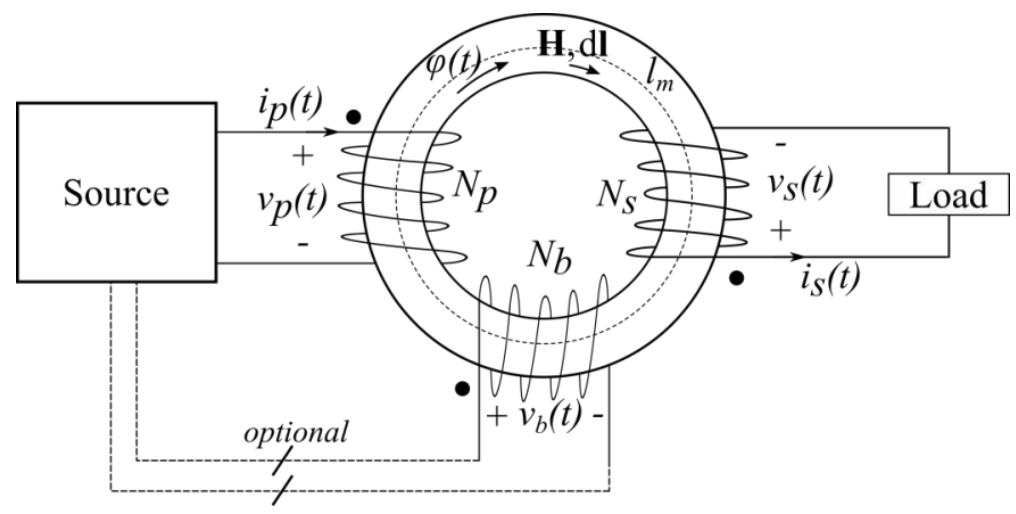

Fig. 1. Simplified diagram of the system with the transformer. 
Journal of Microwaves, Optoelectronics and Electromagnetic Applications, Vol. 20, No. 4, December 2021 DOI: http://dx.doi.org/10.1590/2179-10742021v20i4254768

The primary winding, with $N_{p}$ turns, is supplied with the voltage $v_{p}(t)$. The B-coil, with $N_{b}$ turns, constitutes a magnetic flux sensor and operates always open-circuited, i.e., connected to high impedance circuits such the measurement system and, optionally, to a closed loop control in order to maintain desired waveforms and amplitudes of the flux in the magnetic circuit. In this winding, the counter-electromotive force is also measured. The secondary winding, with $N_{s}$ turns, is connected to the load.

\section{PROBLEM DEFINITION}

A traditional magnetic circuit, commonly used to characterize soft ferromagnetic materials, has overlaid supply and flux measurement windings. An initial version of the three-winding transformer was made by using overlaid windings, as illustrated in the schematic cross section in Fig. 2. After preliminary studies, the test transformer was defined as a toroidal core with 16 electric steel sheets(16 round sheets stacked) with $0.5 \mathrm{~mm}$ thickness, external and internal diameters respectively of $340 \mathrm{~mm}$ and $310 \mathrm{~mm}$, with three windings of 720 turns each. The arrangement of each winding is shown in Fig. 2. The winding for measuring magnetic flux, called the B-coil, was wound in the first layer, while the primary and secondary windings were wound in the second and third layers, respectively. This device was tested with no load to obtain the characteristics of the magnetic material with sinusoidal supply, at various frequencies and induction points in order to segregate the magnetic losses.

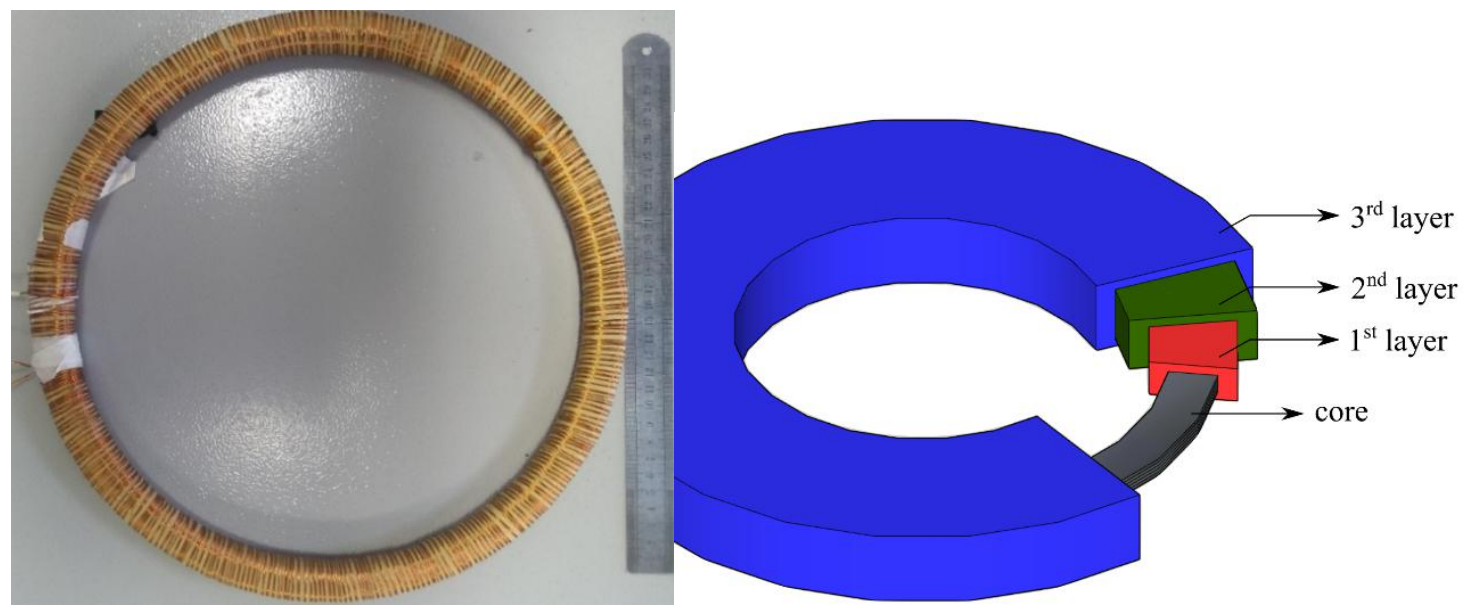

Fig. 2. Image of the magnetic circuit with three windings (left) and its coil layers scheme (right).

After crafting the device, preliminary tests were carried out to investigate methodologies for electric and magnetic measurements, and mainly to evaluate the methods for power flow calculation with energy transfer to the load. In fact, the methods presented in the literature provide different magnetic loss results, as presented in [3] and covered in the present study.

In early tests, it was found that the magnetization loops at loaded condition were different from those obtained with no load. Additionally and consequently, the calculated magnetic losses values were not the same when obtained by PDM (Power Difference Method) and CDM (Current Difference Method), dealt with in [3] and further on, showing the influence of the load connected to the secondary winding. In general, there was an approximate decrease of $8 \%$ compared with the magnetic 
Journal of Microwaves, Optoelectronics and Electromagnetic Applications, Vol. 20, No. 4, December 2021

DOI: http://dx.doi.org/10.1590/2179-10742021v20i4254768

losses at no load. This does not correspond to reality, because for the same induction, the same magnetization loop must be observed, regardless of the load. Thus, the reason for such differences and inconsistencies in the experimental measurements were investigated.

Initially, the issue of using two different sensors for the primary and secondary currents was addressed. A Tektronix measurement system with Hall effect current probes was used: the primary current was measured with a model TCP0030 current probe directly connected to a DPO4104 oscilloscope; the secondary winding current signal, measured with model A6302 probe, was processed by an AM503 amplifier and connected to another oscilloscope channel. The magnetization current, calculated by subtracting the primary current $\left(i_{p}\right)$ by the secondary current $\left(i_{s}\right)$, as indicated in (1), resulted in a noisy signal (see Fig. 3). However, as both windings had the same number of turns, the magnetization current $\left(i_{m}\right)$ could be obtained with a single transducer (model TCP0030) embracing both cables placed in opposite directions, thus physically carrying out the process of (1). For different numbers of turns, this procedure may still be valid if the cables are embraced multiple times according to the transformer turns ratio, although this may become impracticable at some point.

$$
i_{m}(t)=i_{p}(t)-i_{s}(t)
$$

Figure 3 shows experimental B-H loops for magnetization at $10 \mathrm{~Hz}$ with no load (curveNoLoad_l) and with a $10 \Omega$ load (curvesLoad_10R_1_calc and Load_10R_l). The index "_l" indicates that the source is connected to the winding of the second layer and the load is connected to the winding of the third layer. The BH-loop "Load_10R_1_calc" was obtained using the two probes and calculating the magnetization current. The BH-loop "Load_10R_l" was obtained through the single probe method. Comparing the BH-loops with load, an improvement is noted when using only one probe. Nevertheless, the BH-loop is still clearly narrower than with no load.

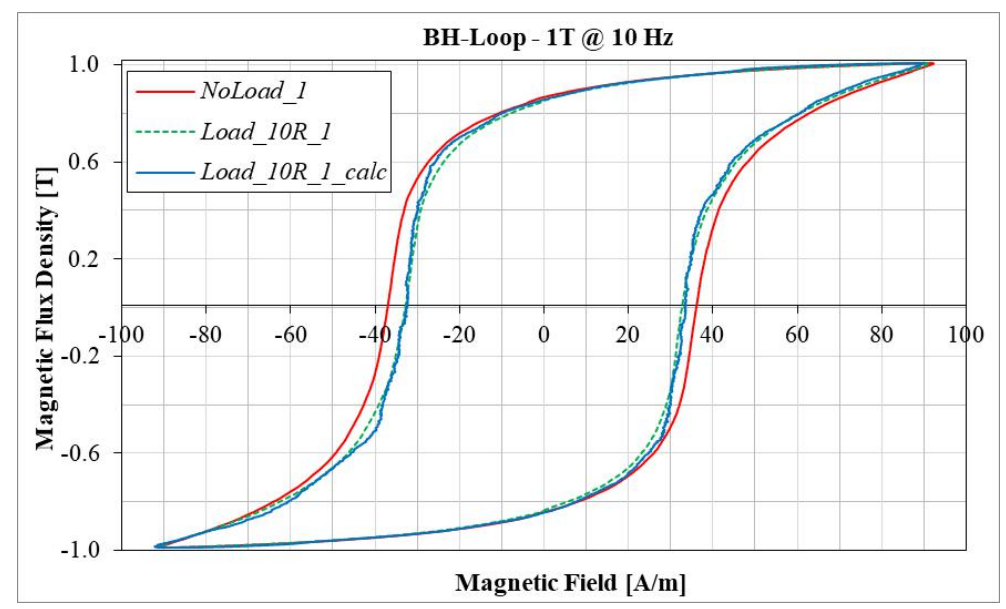

Fig. 3. BH-loops for the 16-sheet toroid at $1.0 \mathrm{~T}$ and $10 \mathrm{~Hz}$, with no load and with a $10 \Omega$ load on the secondary winding.

Tests were performed with other load values to assess its possible influence on the shape of the $\mathrm{BH}-$ loops. With the increase in the load (decreasing values of resistance inserted in the secondary winding), the loops became increasingly narrow. Figure 4 shows magnetic field curves at no-load and at two load conditions ( $5 \Omega$ and $10 \Omega$ ). It can be noticed visually that, with the increase of the load, the 
amplitudes of the measured field tend to decrease.

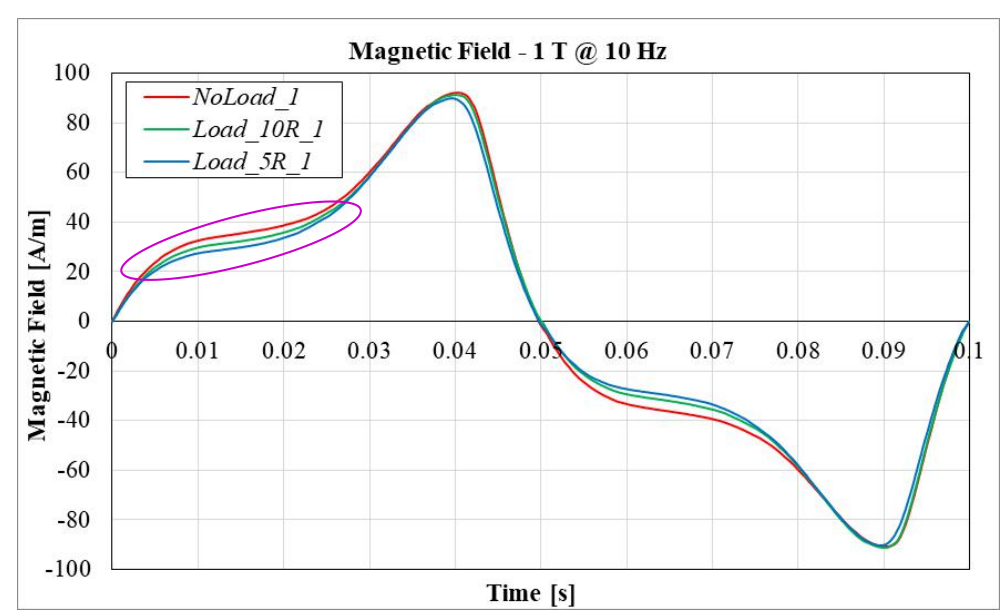

Fig. 4. Magnetic field waveforms, with no load and different loads connected to the third layer winding.

The winding connections were then inverted. The source was connected to the outer ( $3^{\text {rd }}$ layer) winding and the load to the second layer winding, keeping the B-coil in the first layer as a probe. This resulted in a contrary behavior of the BH-loops, i.e., they widen with increasing load. Figure 5 shows the magnetization loops measured with the new configuration, as well as those already shown in Fig. 3. Index "_2" indicates the connection of the source to the third layer winding, and the load to the second layer winding. The loops measured with no load for both configurations are also shown and are practically identical. However, when energy is transferred to the load, the measured magnetic field is greater or less than at no-load condition, depending on the configuration: in the first configuration investigated ( $\_$l), the loop tends to narrow as the load increases; and conversely, in the second configuration (2), the loop expands with increasing load.

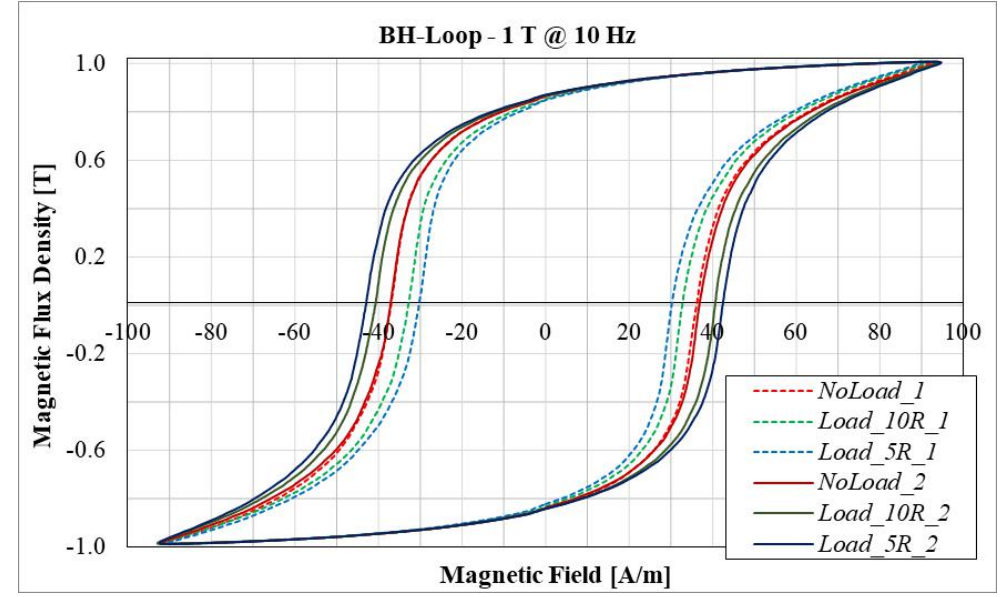

Fig. 5. No load and load operation of the magnetic circuit in two cases of connection of the primary and secondary windings.

To corroborate what has been verified, Fig. 6 shows magnetization and load current waveforms, $i_{m}(t)$ and $i_{s}(t)$, at $1.0 \mathrm{~T}$ and $10 \mathrm{~Hz}$ with a10 $\Omega$ load, measured in the first configuration. The divergence among the magnetic field curves observed in Fig. 4 occurs predominantly in the region where the load current is at its maximum. It is concluded that the load current has an influence on the measurement of the magnetization current, which might undermine the investigation of the behavior of magnetic 
losses under PWM voltage regime when the device processes energy for a load.

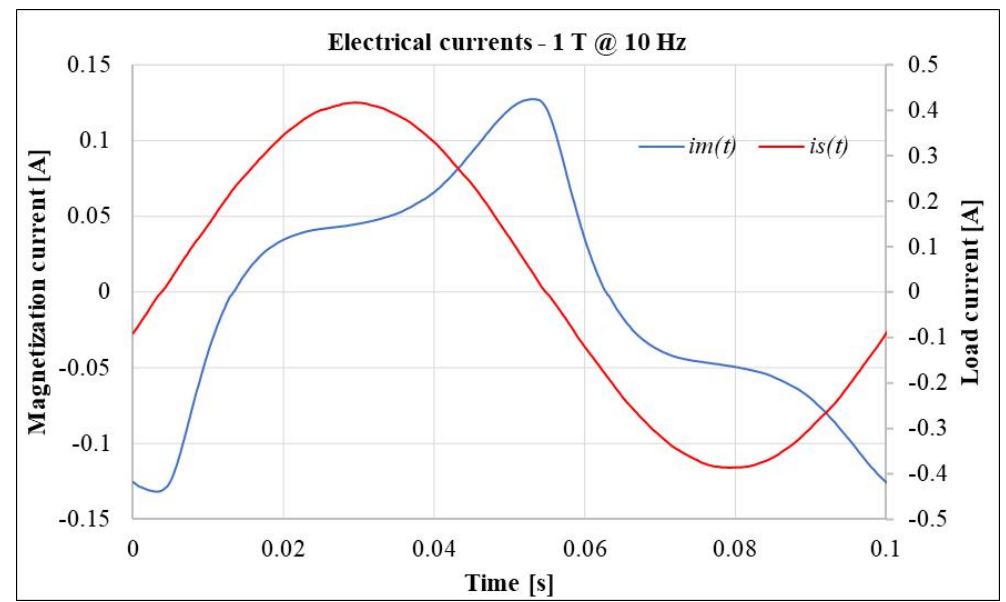

Fig. 6. Magnetization and load currents for case 1.

To solve this experimental issue, a new configuration was conceived with primary and secondary conductors twisted together. This and the former configurations were simulated through finite element calculations. The following section presents qualitative results obtained through simulation with the FEM (Finite Element Method).

\section{MAGNETIC CIRCUIT SIMULATION WITH FEM}

Electromagnetic devices with different windings were simulated in EFCAD [7]. The dimensions, core material, number of turns, spacing, etc. are not the same of the assembled devices. The simulation carried out was linear with generic electrical steel without saturation and losses. Thus, the simulation results are conceptual and serve to help clarify the issue in a qualitative way.

The first simulations considered a device with concentric windings, whose calculation domain is illustrated in Fig. 7. The supply is connected to the inner layer, represented in red, and the load to the outer layer, represented in green. An appropriate air box, not shown in the figure, was used.

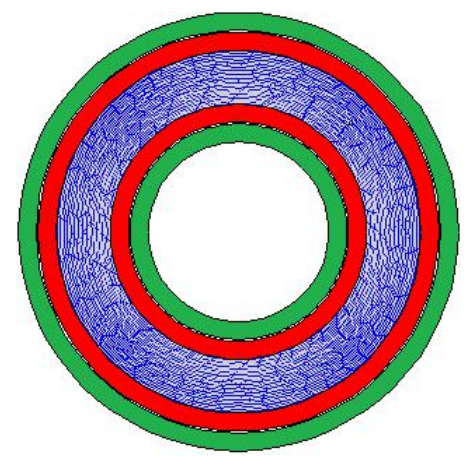

Fig. 7. Calculation domain of the simulated electromagnetic device supplied through the inner layer winding.

The device was simulated at two conditions, with and without load. At each condition, the magnetic flux density (induction) waveform was obtained at a point in the center of the core, along with the primary and secondary current waveforms. In the no-load simulation, the magnetization current is equal to the primary current. In the loaded condition, the magnetization current was calculated as the difference between the simulated primary and secondary currents. 
Journal of Microwaves, Optoelectronics and Electromagnetic Applications, Vol. 20, No. 4, December 2021 DOI: http://dx.doi.org/10.1590/2179-10742021v20i4254768

Figure 8 shows the simulated induction waveforms in the core under no load and load conditions. At loaded condition, there was a decrease in the peak induction in the core. This is expected due to the voltage drop in the resistance of the primary winding, as the supply voltage was not changed to maintain the induction amplitude. This does not influence the qualitative study of the question. The primary and secondary current waveforms are shown in Fig. 9 for both conditions.

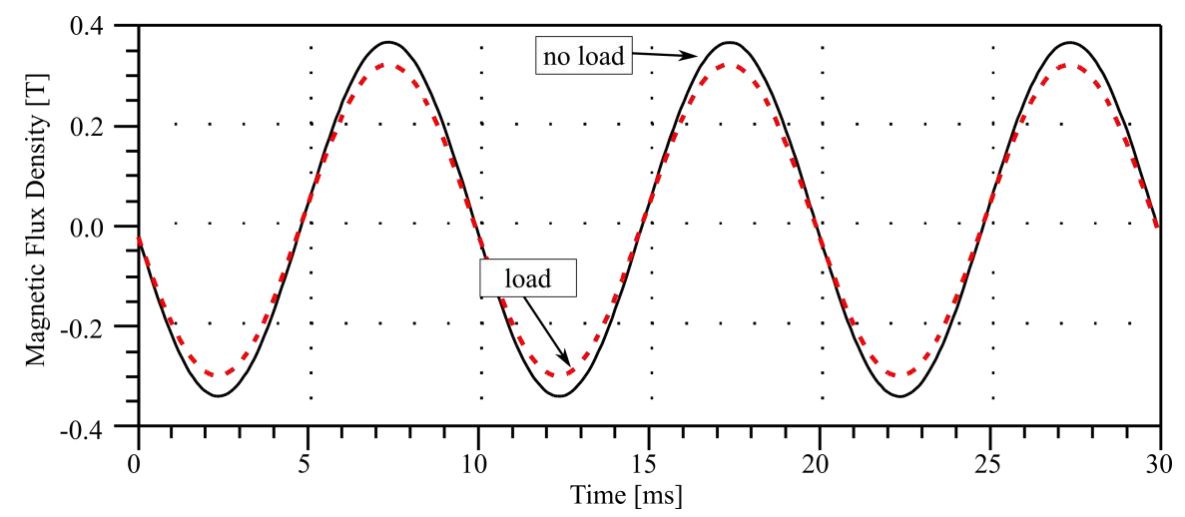

Fig. 8. Induction waveforms in the core, with overlaid windings.

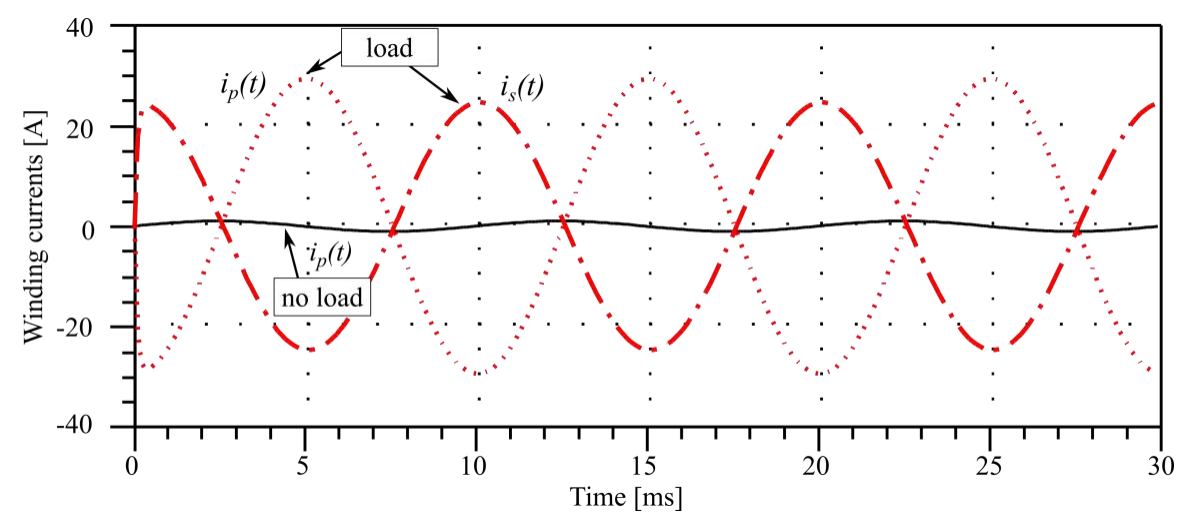

Fig. 9. Primary and secondary current waveforms at no-load and loaded conditions, with overlaid windings.

The simulated waveforms of the magnetization current, calculated as the difference between the primary and secondary currents at both conditions, are shown in Fig. 10. There is a notable difference between the waveforms of the magnetization current for the two conditions.

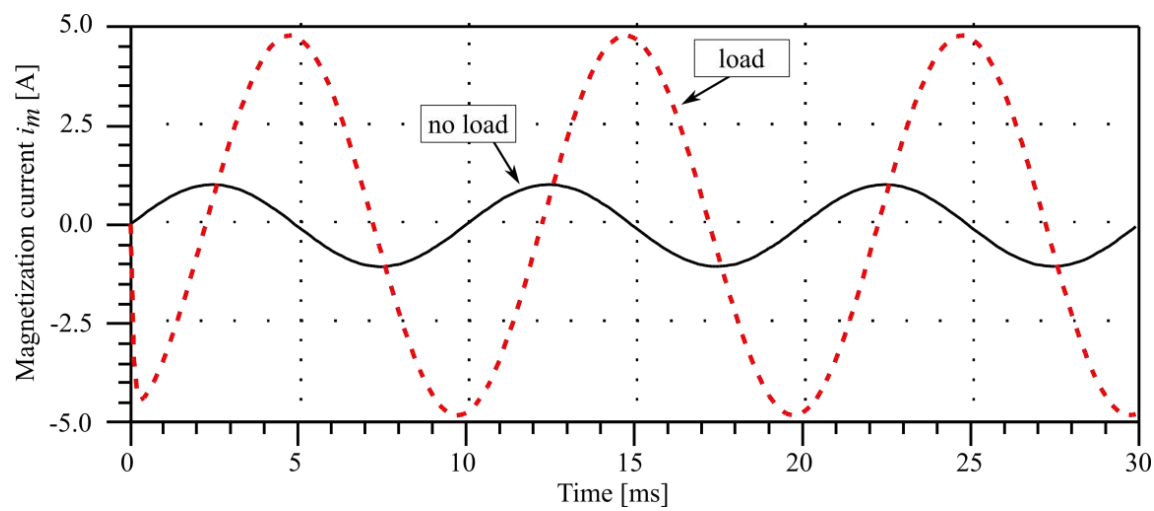

Fig. 10. Magnetization current waveforms for no load and load condition with overlaid windings.

Numerical simulations were then performed following a strategy of alternating the position of the windings along the circumference, as shown in Fig. 11. This strategy was adopted to represent the 
twisted primary and secondary windings of the electromagnetic device.

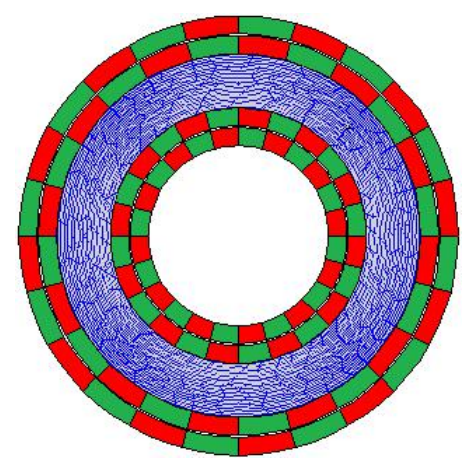

Fig. 11. Simulated calculation domain with alternated primary and secondary windings.

The induction waveforms in the core for this new configuration are shown in Fig. 12. Similarly the previous case, the peak induction decreases when load is added to the secondary winding.

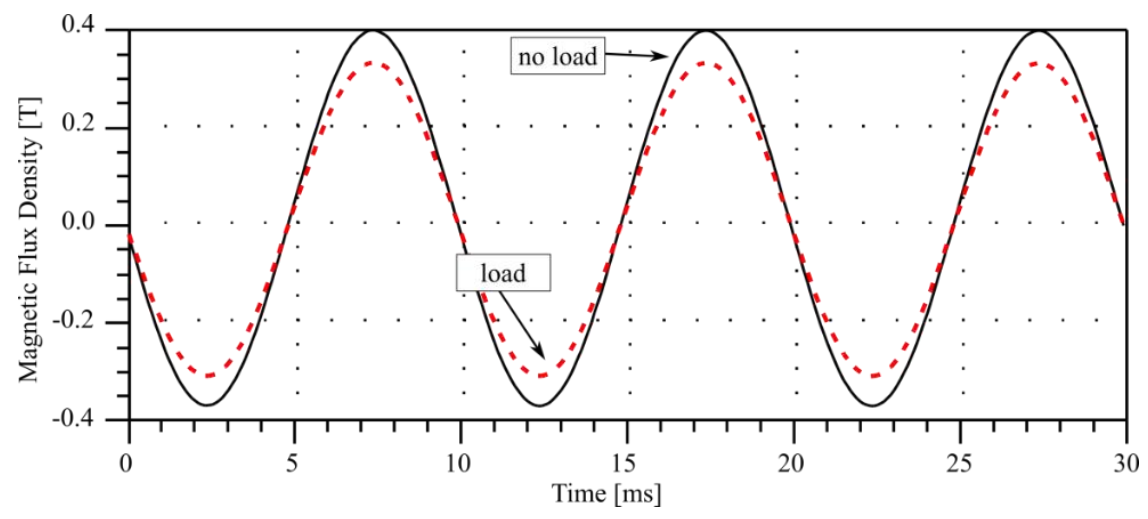

Fig. 12. Induction waveforms in the core as a function of time, with alternated windings.

The calculated magnetization current waveforms are shown in Fig. 13. There is still a difference in amplitude between the waveforms, but much smaller than in the case of overlaid windings. Comparing Fig. 10 with Fig. 13, the phase difference between the no-load and loaded conditions with alternated windings is almost imperceptible visually, which does not happen with overlaid windings.

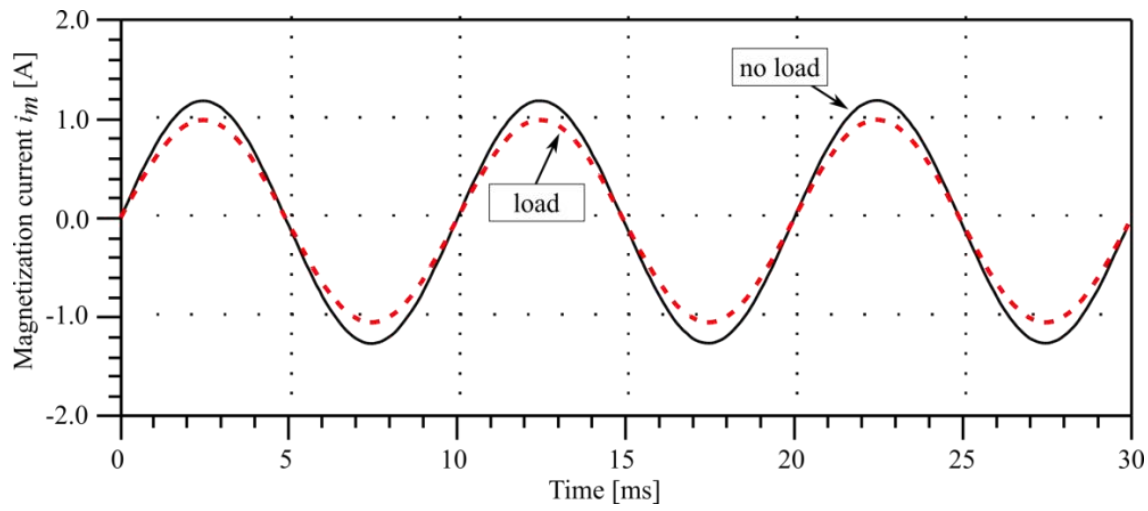

Fig. 13. Magnetization current for the no-load and loaded conditions, with alternated windings.

The experimental results presented so far and, mainly, the results obtained through numerical simulation indicate that the differences observed experimentally in the magnetization current are due to the effects of the leakage flux. The following section presents experimental results with the device equipped with twisted windings. 
Journal of Microwaves, Optoelectronics and Electromagnetic Applications, Vol. 20, No. 4, December 2021 DOI: http://dx.doi.org/10.1590/2179-10742021v20i4254768

\section{EXPERIMENTAL RESULTS WITH THE IMPROVED THREE-WINDING TRANSFORMER}

An improved device was built with primary and secondary windings twisted together and wound in the same layer on the same magnetic core with 16 steel sheets previously presented. Table I presents the constructive data of the electromagnetic device.

\begin{tabular}{ccc} 
TABLE I. CONSTRUCTIVE DATA OF THE MAGNETIC CIRCUIT USED IN TEST & \multicolumn{2}{c}{ Unit } \\
\hline Quantity & Value & $\mathrm{mm}$ \\
\hline Outer diameter & 340 & $\mathrm{~mm}$ \\
Inner diameter & 310 & $\mathrm{~mm}$ \\
Sheet thickness & 0.5 & - \\
Number of sheets & 16 & $\mathrm{~g}$ \\
Mass & 930.54 & $\mathrm{~g} / \mathrm{cm}^{3}$ \\
Specific mass & 7.595 & turns \\
$N_{p}$ & 360 & turns \\
$N_{s}$ & 360 & turns \\
$N_{b}$ & 720 & $\mathrm{~m}$ \\
Magnetic length & 1.02102 & $\mathrm{~m}^{2}$ \\
Cross section & 0.00012 & - \\
Class material & M530-50A &
\end{tabular}

Tests were performed at no-load and loaded conditions with $2.5 \Omega$ and1.67 $\Omega$ resistors. The magnetization loops are shown in Fig. 14, for $1.0 \mathrm{~T}$ peak induction at the frequency of $10 \mathrm{~Hz}$. Also shown is the BH-loop "No load case 1" obtained in the configuration with overlaid windings at noload condition. All four loops are practically identical, even in the cases where energy is transferred to the load, with primary and secondary windings twisted together.

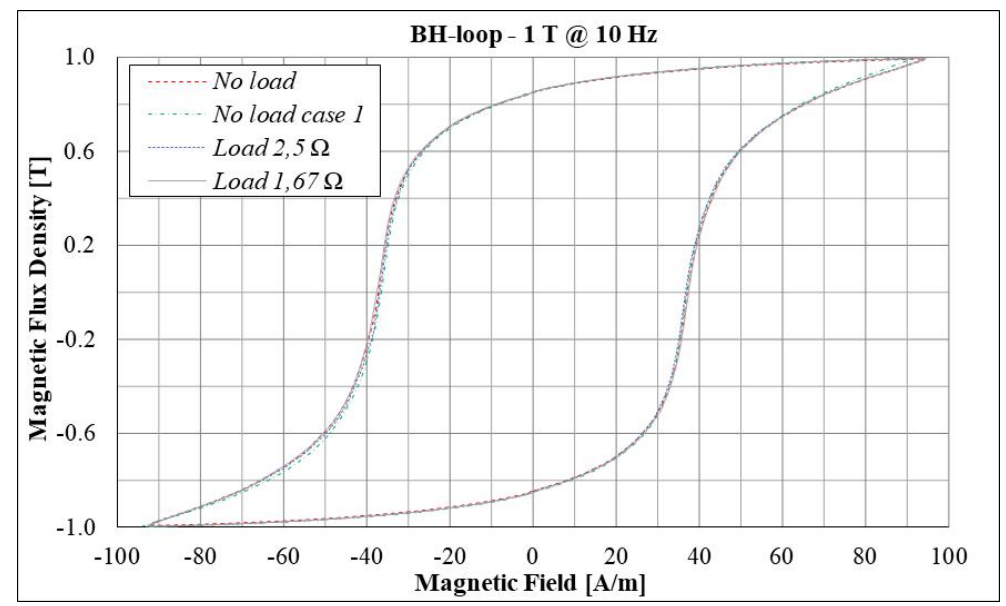

Fig. 14. BH-loops for the device with twisted windings with no load and at different load conditions.

This device was thus validated for the subsequent experimental investigation of the iron losses behavior under different supply regimes, namely sinusoidal and PWM at three levels, and under different load conditions.

\section{DETERMINATION OF THE MAGNETIC LOSS VALUES IN THE THREE-WINDING TRANSFORMER}

The studied device can be modeled by an equivalent electric circuit, as shown in Fig. 15, where $R_{p}$ and $R_{s}$ are respectively the resistances of the primary and secondary windings, $L_{d p}$ and $L_{d s}$ are the 
leakage inductances of the respective windings, $R_{f e}$ is the resistance related to core losses, $L_{m}$ is the magnetizing inductance and $R_{L}$ is the load resistance connected to the secondary winding. The parasitic capacitances and its effects are neglected.

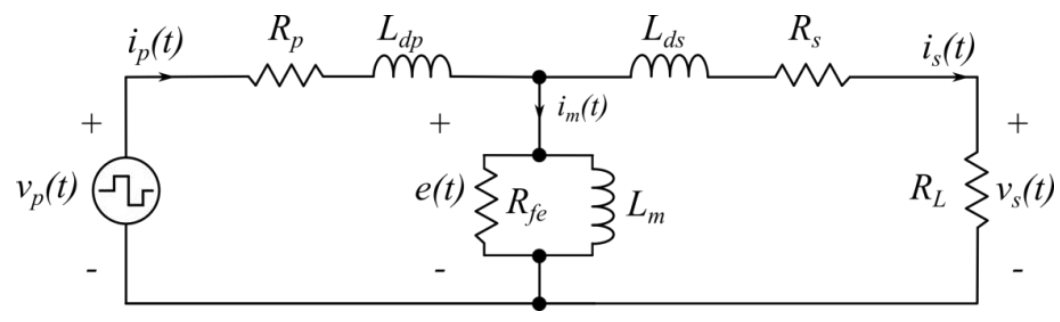

Fig. 15. Equivalent electrical circuit of the three-windings device.

It is possible to write the equations for energy losses in the primary and secondary windings based on the respective electrical quantities. In spite of the possibility of measuring the windings and load resistances, as performed in [3], it is interesting to use only the voltage and electric current quantities in the calculation of the dissipated power in order to avoid errors associated to the resistance values, which vary with frequency and temperature. The voltage and current waveforms in both windings are known, as well as the counter electromotive force (EMF), $e(t)$, measured with the B-coil.

Next, the two methods used in [3] to determine the values of magnetic losses in the device's core are presented and discussed.

\section{A. Energy balance method}

The energy balance method used here, characterized by (2), is an improvement of [3]. The input power $P_{\text {in }}$ corresponds to the power dissipated in the magnetic circuit $P_{f e}$, in the primary $P_{R p}$ and secondary $P_{R s}$ windings, and consumed by the load $P_{\text {load. }}$ In [3], the PDM method uses measured resistance and RMS (root mean square) current values to calculate $P_{R p}$ and $P_{R s}$.

$$
P_{f e}=P_{\text {in }}-P_{R p}-P_{R s}-P_{\text {load }}
$$

The input power is calculated through (3) with the primary voltage $v_{p}(t)$ and current $i_{p}(t)$ waveforms. The power dissipated in the primary winding $P_{R p}$ is calculated by (4) using the primary current $i_{p}(t)$ and the voltage drop in the primary winding as a function of the primary voltage $v_{p}(t)$ and the counter EMF $e(t)$ measured through the B-coil. Likewise, $P_{R s}$ is calculated through (5) using the secondary current $i_{s}(t)$, the counter EMF $e(t)$ and the secondary voltage $v_{s}(t)$. The power dissipated in the load $P_{\text {load }}$ is obtained similarly as a function of the secondary voltage and current waveforms.

$$
\begin{gathered}
P_{\text {in }}=\frac{1}{T} \dot{\mathrm{s}}_{T} \quad v_{p}(t) i_{p}(t) d t \\
P_{R p}=\frac{1}{T} \dot{\mathrm{s}}_{T}\left[v_{p}(t)-e(t)\right] i_{p}(t) d t \\
P_{R s}=\frac{1}{T} \dot{\mathrm{s}}_{T}\left[e(t)-v_{s}(t)\right] i_{S}(t) d t
\end{gathered}
$$

Once these values are known, the iron losses, $P_{f e}$, can be determined from (2). This value, in watts, corresponds to the magnetic loss in the core material for an operating condition withgiven values of 
Journal of Microwaves, Optoelectronics and Electromagnetic Applications, Vol. 20, No. 4, December 2021 DOI: http://dx.doi.org/10.1590/2179-10742021v20i4254768

peak induction $B_{p}$ and frequency $f$. This procedure is used when the magnetic circuit is processing energy, that is, when there is load on the secondary winding. At no-load, (8) is used instead, with $i_{m}(t)=i_{p}(t)$.

\section{B. Current difference method}

A second method - CDM was studied by [3]. Iron losses are calculated in a classical manner, i.e., from the product of the magnetizing current $i_{m}(t)$ and the induced voltage in the B-coil. In this method, the secondary current $i_{s}(t)$ must be referenced to the primary winding as $i_{s}{ }_{s}(t)$, according to (6). Thus, the current in the magnetizing branch $i_{m}(t)$ can be obtained through (7), and the iron losses through (8), in watts.

$$
\begin{gathered}
i_{s}^{\prime}(t)=\frac{N_{s}}{N_{p}} i_{s}(t) \\
i_{m}(t)=i_{p}(t)-i_{s}(t) \\
P_{f e}=\frac{1}{T} \dot{\mathrm{s}}_{T} e(t) i_{m}(t) d t
\end{gathered}
$$

\section{STUDY OF THE EQUIVALENT ELECTRICAL CIRCUIT TIME CONSTANT}

Considering the system linear, one way to characterize the behavior of the test device is by changing the value of the system time constant $\tau$, defined by the inductances and resistances of the system, as a function of the load variation. Figure 16 shows a simplification of the equivalent electrical of Fig. 15. The leakage flux inductances are neglected, as the magnetization inductance is relatively higher. The resistances of the secondary branch are grouped as a single $R_{S}$,resistance.

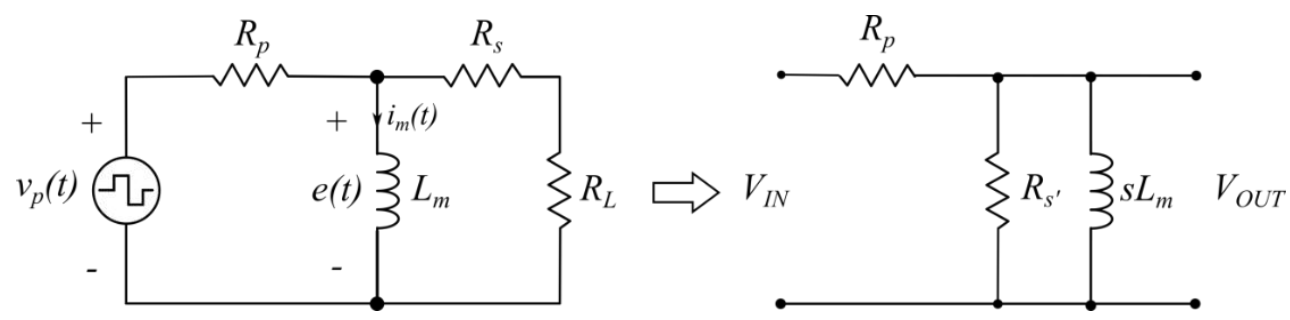

Fig. 16. Simplified equivalent electrical circuit of the three-windings device.

The transfer function $G(s)$ of the $V_{\text {OUT }} / V_{I N}$ ratio in the complex frequency domain, given by the development of the voltage divider equation, results in (9).

$$
G(s)=\frac{L_{m} R_{s^{\prime}}}{R_{p} R_{s^{\prime}}} \frac{s}{s L_{m} \frac{R_{p}+R_{s^{\prime}}}{R_{p} R_{s^{\prime}}}+1}
$$

A resistor $R$ is defined as the parallel association of $R_{p}$ and $R_{s^{\prime}}$, according to (10).

$$
R=\frac{R_{p} R_{s^{\prime}}}{R_{p}+R_{s^{\prime}}}
$$

Substituting (10) in (9) results in (11).

$$
G(s)=\frac{L_{m}}{R_{p}} \frac{s}{s \frac{L_{m}}{R}+1}
$$


Rewriting (11) in the canonical form of a first order system results in (12), where the time constant $\tau$ is given by the ratio $L_{m} / R$ and the term $R_{s^{\prime}} /\left(R_{p}+R_{s^{\prime}}\right)$ corresponds to the gain of the transfer function.

$$
G(s)=\frac{R_{s^{\prime}}}{R_{p}+R_{s^{\prime}}} \frac{s}{s+\frac{R}{L_{m}}}
$$

Thus, the time constant $\tau$ can be expressed according to Eq. (13).

$$
\tau=L_{m} \frac{R_{p}+R_{s^{\prime}}}{R_{p} R_{s^{\prime}}}
$$

Taking into account the assumption of constant parameters and that the magnetization inductance is a function of the geometry of the device and of the permeability $\mu$ of the core material, its value can be expressed by (14), assuming constant values of magnetic path $l_{m}$ and effective section $S$. The greater the magnetization inductance, the greater is the value of the time constant. Regarding the quality of the ferromagnetic material, the greater the magnetic permeability, the greater is the time constant.

$$
L_{m}=\frac{N_{p}^{2} \mu S}{l_{m}}
$$

The primary and secondary winding resistances are proportional to the number of turns, to the geometry of the coil and to the diameter of the conductors. The value of $R_{p}$ is constant and $R_{s^{\prime}}$ changes according to the load. A constant $\alpha$ is defined to relate $R_{s^{\prime}}$ and $R_{p}$, according to (15), so that (13) can be rewritten as a function of $\alpha$, according to (16).

$$
\begin{gathered}
R_{S^{\prime}}=\alpha R_{p} \\
\tau=\frac{L_{m}}{R_{p}} \frac{1+\alpha}{\alpha}
\end{gathered}
$$

The evolution of the normalized time constant $\tau / \tau_{\min }$ (where $\tau_{\min }=L_{m} / R_{p}$ ) as a function of $\alpha$ is shown in Fig. 17. The higher the value of $\alpha$, the lower is the value of $\tau$, which corresponds to greater current and voltage $e(t)$ variations in the magnetizing inductance for an applied voltage step, for example. Under the aspect of pulsed regimes, this fact results in greater variations in the magnetic field and induction, causing increased magnetic losses.

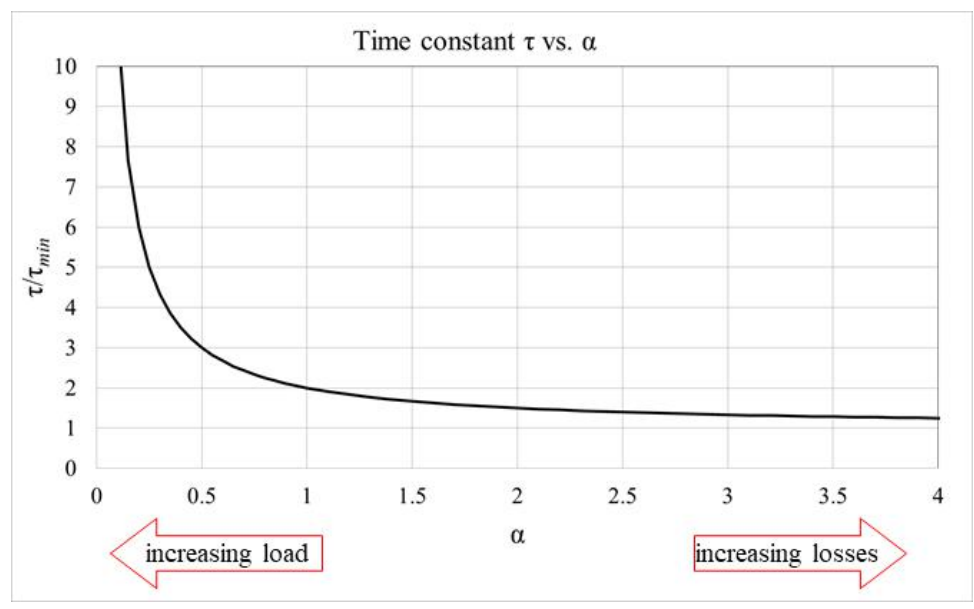

Fig. 17. Time constant normalized as a function of $\alpha$. 
Journal of Microwaves, Optoelectronics and Electromagnetic Applications, Vol. 20, No. 4, December 2021

DOI: http://dx.doi.org/10.1590/2179-10742021v20i4254768

The main conclusions from this analysis are related to the time constant $\tau$ and its relationship with the magnetizing inductance and with the resistances of the primary and secondary windings associated with the load. The variable $\alpha$ was introduced as a load factor, enabling a qualitative and quantitative evaluation of the behavior of the time constant as a function of the secondary load. In the next section, the influence of the primary resistance in the formation of internal magnetization loops and the consequent increase in the magnetic losses will be observed experimentally.

\section{TESTS WITH THREE-LEVEL PWM SOURCE}

This section presents tests and analysis of the losses obtained at no-load and loaded conditions, this time with a three-level PWM supply in the primary winding, since the static converters do not impose the PWM waveform in the EMF, $e(t)$. The tests were performed at different conditions of peak induction, with a constant fundamental frequency of $10 \mathrm{~Hz}$ and switching frequency $f_{s}$ of $70 \mathrm{~Hz}$. The magnetic losses assessed at this work are related to hysteresis losses and mainly related to the minor hysteresis loops (the main loop was kept constant). As the goal was to evaluate only the hysteresis losses due to the formation of minor loops, it was decided to carry out the tests with a low fundamental frequency $(10 \mathrm{~Hz})$, because in this situation the dynamic losses can be neglected. Relatively high switching frequencies can contribute to the increase in dynamic losses [11] and causes non-linear phenomena related to the attenuation of flux penetration in ferromagnetic material, which are undesirable issues for the study in this present paper. In this context, it was decided to work with a relatively low switching frequency $(70 \mathrm{~Hz})$ in order to contemplate the question of minor loops with evidence, presenting an easy visualization of the hysteresis loss behavior in the context of the present investigation.The name PWM3 will be used in the sequence to indicate PWM power at three-levels [8], [9].

\section{A. Changing the load resistance}

The magnetic losses and magnetization loops were obtained from tests where resistive loads were connected to the secondary winding, causing the magnetic circuit to transfer energy to the load. In each of the tests, the amplitude of the supply voltage was adjusted in order to maintain the peak induction value $B_{\mathrm{p}}$ at given levels between $0.6 \mathrm{~T}$ and $1.4 \mathrm{~T}$.

Figure 18 shows values of total losses obtained through the CDM (_CDM index) and energy balance ( $P D M$ index) methods with a $5 \Omega$ load connected to the secondary winding. For comparison purposes, the magnetic losses at no-load condition are also presented, as well as the percent difference between the losses with load compared to those with no load. These differences vary in the range of $\pm 2 \%$ for both methods. 


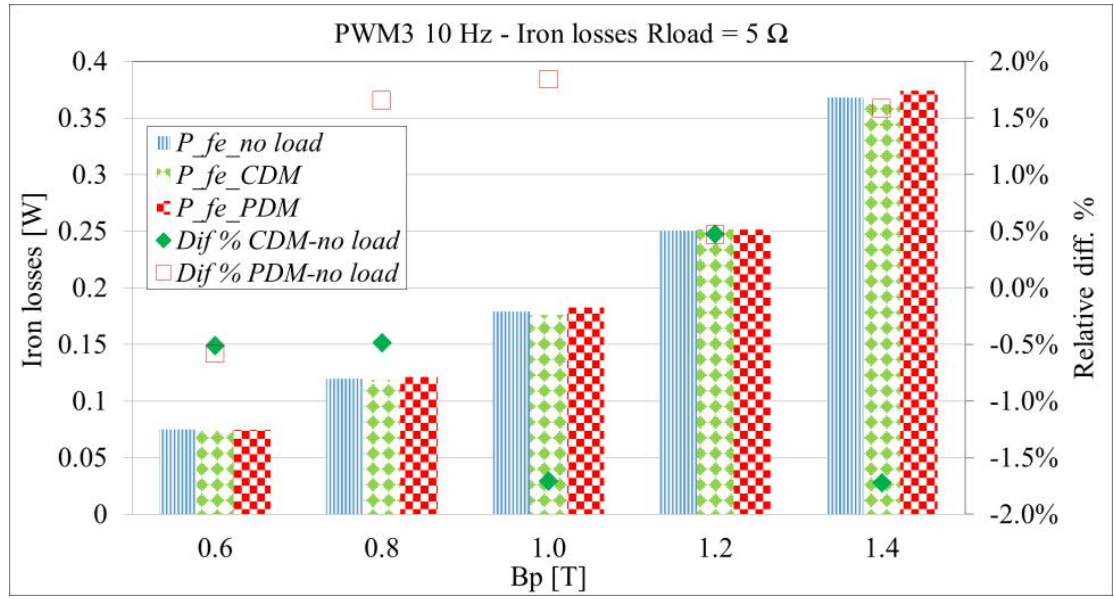

Fig. 18. Total iron losses for the circuit fed with PWM voltage at three levels, $5 \Omega$ load connected to the secondary winding.

Figure 19 shows the magnetization loops for the $1.4 \mathrm{~T}$ peak induction with different load resistances, and Fig. 20 shows details of the behavior of the inner loops as a result of changing load conditions. In these conditions, there are only six inner loops in the main magnetizing loop. When the load increases ( $R_{L}$ decreases), the area of the inner loop tends visibly to decrease. The trend indicates that, with increasing load, the magnetic loss decreases in relation to the no load condition (see [10]).

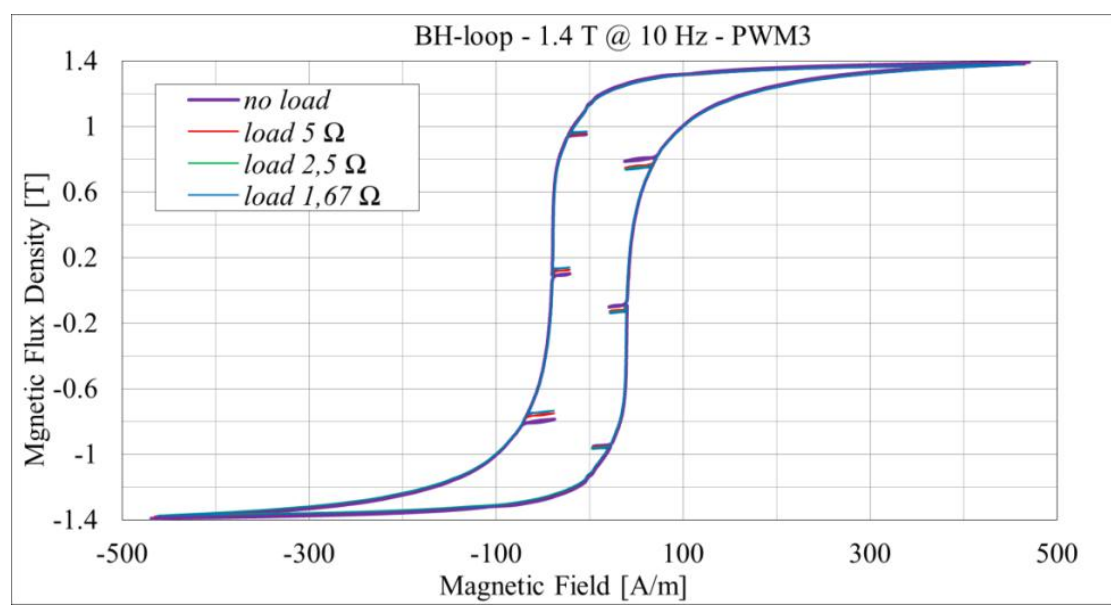

Fig. 19. Magnetizing loops for $B_{p}=1.4 \mathrm{~T}$ at $10 \mathrm{~Hz}$, fed with PWM voltage at three levels. Device with no load (caption $n o$ load) and with three load values (caption: load $5 \Omega$, load $2.5 \Omega$ and load $1.67 \Omega$ ).

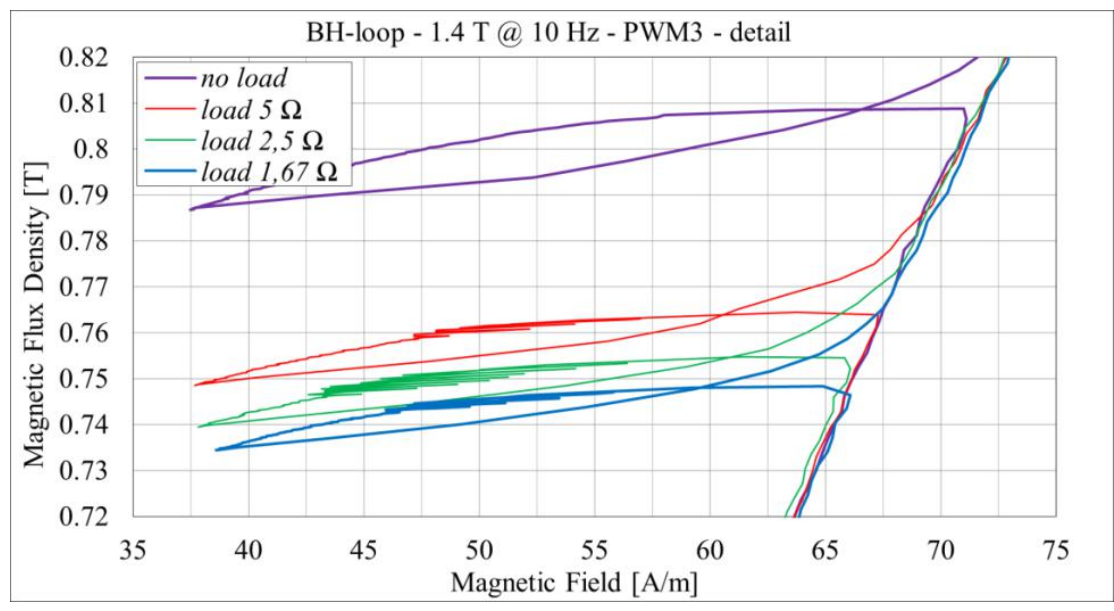

Fig. 20. Detail of the inner loops of the BH-loop in Fig. 19. 
Journal of Microwaves, Optoelectronics and Electromagnetic Applications, Vol. 20, No. 4, December 2021 DOI: http://dx.doi.org/10.1590/2179-10742021v20i4254768

\section{B. Changing the load resistance and the primary coil resistance}

As exposed in section VII, there is a main time constant $\tau$ that governs the dynamic behavior of the electromagnetic device. Also as shown, changes in the primary resistance $R_{p}$ influence the value of $\tau$. Under this approach, the behavior of magnetic losses resulting from changes in the primary resistance is investigated in this section. Two additional resistance values, 5 and $10 \Omega$, were used to increase $R_{p}$.

Figure 21 shows magnetization loops of the core of the electromagnetic device at $1.0 \mathrm{~T}$ at $10 \mathrm{~Hz}$, with no load, without the addition of a resistor in the primary and adding the resistors of $10 \Omega$ or $5 \Omega$. The increase in the primary resistance corresponds to an increase in the area of the inner loops. With a higher value of electrical resistance in the primary, the value of the time constant $\tau$ is smaller, increasing the variation of the induction in the same time interval, thus increasing the area of the smaller loops and, consequently, the magnetic losses.

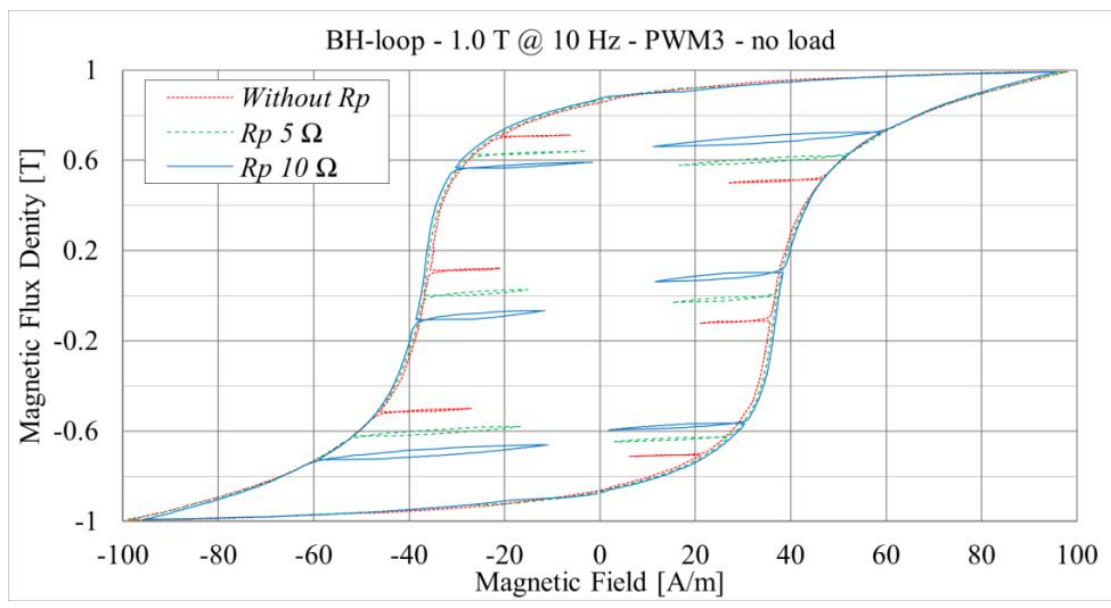

Fig. 21. BH-loops at no-load for different primary resistance values.

The waveforms of the EMF, $e(t)$, are shown in Fig. 22. The highlighted regions mark the occurrence of opposite polarity between the instantaneous values and the fundamental component. This rule, addressed in [8] and [11], defines the occurrence of the formation of internal loops, as shown in Fig. 21. Note that when the resistance of the primary winding increases, the peak voltage values increase induced when the polarity is opposite to the fundamental.

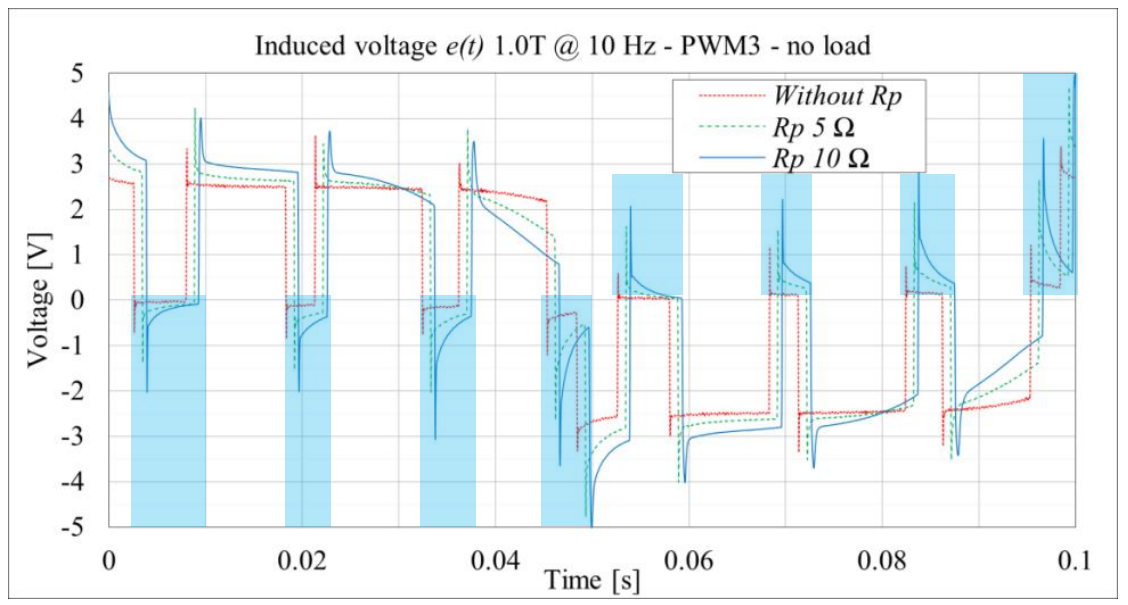

Fig. 22. Induced voltage curves for three values of $R_{p}$; operating point $1.0 \mathrm{~T}$ at $10 \mathrm{~Hz}$; and device with no load. 
Journal of Microwaves, Optoelectronics and Electromagnetic Applications, Vol. 20, No. 4, December 2021 DOI: http://dx.doi.org/10.1590/2179-10742021v20i4254768

In order to evaluate the magnetic losses when the device transfers energy to a load, a $5 \Omega$ load resistor was added to the secondary winding, and the previous tests were repeated varying the resistance of the primary. The results are shown in Fig. 23, along with the no-load results. With the $5 \Omega$ load, the iron losses increased $2.3 \%$ and $2.5 \%$ while the primary additional resistance was subsequently increased. At no-load condition, the losses increased $1.8 \%$ and $3.6 \%$. This means that, at no-load, the losses are comparatively greater and the effect of the primary resistance is more prominent. The increase in the iron losses observed with a $10 \Omega$ additional primary resistance at no load is $50 \%$ greater than at the tested loaded condition.

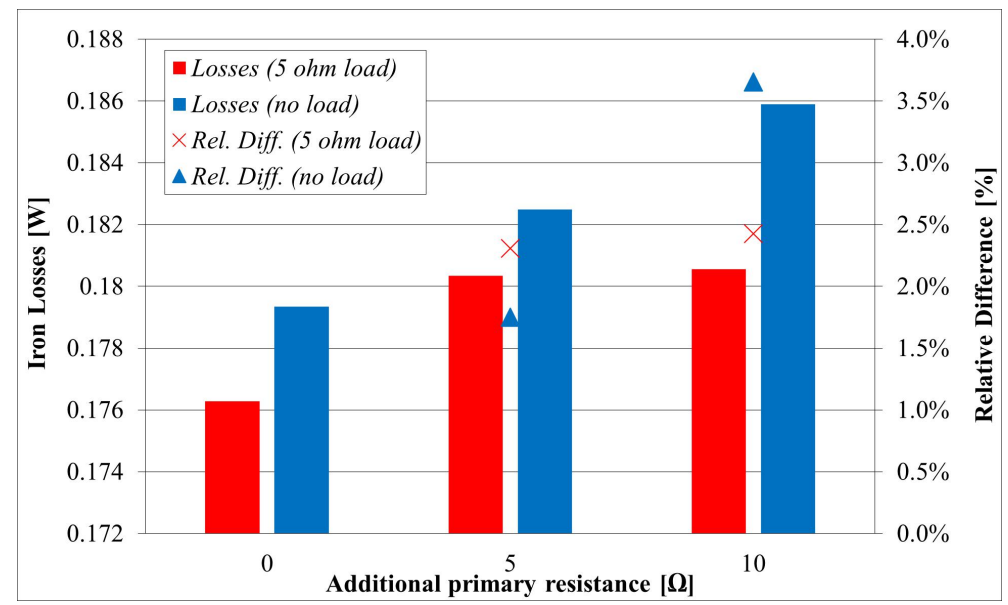

Fig. 23. Effect of $R_{p}$ variation on the iron losses at $1.0 \mathrm{~T}, 10 \mathrm{~Hz}$ at two conditions: no load and $5 \Omega$ load.

\section{CONCLUSIONS}

In the literature on magnetic losses and PWM supply voltage there are conclusions that attribute the increase in magnetic losses mainly to dynamic losses, and do not deals carefully at the minor hysteresis loops behavior. This present investigation provides a study of the behavior of hysteresis loss that opens the way for new approaches and understanding of the behavior of magnetic losses in electromagnetic devices under PWM power. The study collaborates in the elucidation of issues not addressed in the literature on the arising of minor hysteresis loops.

This paper addressed issues related to experimental difficulties in designing electromagnetic devices for studies on magnetic losses when there is energy processing for a load. The effects of leakage fluxes related to the supply and load currents undermine the application of traditional methodologies for determining magnetic losses. The supply and load windings must be wound in such a way as to limit the influence of the leakage fluxeson the measured current waveforms. Without applying this methodology, the experimental investigation provided wrong values of losses and hysteresis loops when there was energy transfer to a load. In addition to solving this problem, the twisting of the primary and secondary conductors also approximated the losses values measured by both the PDM and CDM methods, showing that both methods are possible to be applied safely. In [3] the values obtained in each method were slightly different. This is an additional contribution of the present paper. Regarding the application of the CDM method, the use of a single transducer for 
Journal of Microwaves, Optoelectronics and Electromagnetic Applications, Vol. 20, No. 4, December 2021

DOI: http://dx.doi.org/10.1590/2179-10742021v20i4254768

measuring the net magnetizing current resulted in cleaner waveforms and hysteresis loops. This technique is necessary when it is not possible to accurately process the waveforms from different sensors. For transformers with non-unitary transform turns ratio, this technique may still be applicable, provided that the cables are embraced multiple times according to the turns ratio. However, this may become impracticable at some cases, e.g., non-integer turns ratio.

It was found that there are minor magnetization loops when the electromagnetic device is supplied with a three-level PWM voltage waveform, because the induced voltage has instantaneous values with polarity opposite to the fundamental. For multilevel PWM waveforms with the induced voltage values with instantaneous values opposite to the fundamental polarity, internal hysteresis loops will also appear. No work has been found in the literature reporting this behavior, since the experimental investigation methodology of previous works consisted on exciting the device by imposing the threelevel PWM waveform in the electromotive force $e(t)$ [8], [9], [11]. Other studies on the issue overlooked the effects of the primary winding impedance [3]. This is the main and original contribution of this present work. With this approach, there is an indication that the main cause to the increase in magnetic losses (appearance of minor loops) in pulsed regimes is due to the primary winding resistance. This phenomenon probably occurs even more seriously when the power waveform of the device is with PWM at two levels, where naturally the internal loops are present [8], [9]. Continuing the investigative work, the two level PWM waveforms will be explored with the methodology presented in this paper.

Traditionally in procedures for investigating the behavior of magnetic materials, the three-level PWM waveform is imposed on the electromotive force, with no formation of minor loops. Contrarily, when the device is powered with a three-level PWM voltage waveform, minor loops appear. In this condition and in theoretical approaches, there would be no formation of minor loops when it is assumed that the resistance of the excitation winding is null. According to the electrical equivalent circuit, when the device processes energy for a load and the supply voltage is null during a time interval, there is an impedances parallelism that increases the time constant. This fact decreases the amplitude variations of the induced voltage and, consequently, of the local induction in the regions where minor loops are formed. Thus, in terms of increase in the hysteresis losses, the worst-case scenario for pulsed supply regimes occurs when the device operates at no load. A time constant relationship between the magnetization inductance and the resistances (resistances of windings and load) is proposed in order to help designers to evaluate the increases tendency of the minor hysteresis loops areas.

The reference [3] shows values of losses obtained with the CDM methodology different from those obtained with the PDM. Although both methods have inherent inaccuracies, the improvement of the PDM power difference method carried out in this work, as well as the application of experimental rigor, showed that the loss values obtained by both methods are close.

The differences in the values of hysteresis losses obtained in this work are relatively small, since 
Journal of Microwaves, Optoelectronics and Electromagnetic Applications, Vol. 20, No. 4, December 2021

DOI: http://dx.doi.org/10.1590/2179-10742021v20i4254768

the pulsed waveform has low fundamental and switching frequencies, and consequently only six minor loops are formed. With higher ratios of switching to fundamental frequencies, more minor loops are formed and the differences are expected to become greater. The conclusions have more of a qualitative and indicative nature of the behaviors and phenomena addressed. However, it is estimated that the original conclusions that were drawn point towards a continuation of the investigations aiming to contribute to the studies of magnetic losses in devices supplied with PWM voltage.

There are many conclusions of studies in the literature that attribute the increase in magnetic losses only to dynamic losses and do not look carefully at the formation of minor hysteresis loops. This present investigation provides a study of the behavior of hysteresis loss that opens the way for new approaches and understanding of the behavior of magnetic losses in electromagnetic devices under PWM power supply. The present study collaborates in the elucidation of issues that are pending to be analyzed with greater clarity.

\section{ACKNOWLEDGMENT}

The authors thank the National Council for Scientific and Technological Development - CNPq for the financial support in the form of a scholarship.

\section{REFERENCES}

[1] G. A. McCoy e J. G. Douglass, Energy-Efficient Electric Motor Selection Handbook, Revision 3. Portland, OR: Bonneville Power Admin., 1993.

[2] W. de L. Pires, "Estudo do comportamento das perdas no ferro em motores de indução alimentados por conversores de freqüência", In Portuguese. Master's Thesis. Department of Electrical Engineering. Federal University of Santa Catarina, 2008.

[3] T. Sasayama, M. Morita, e M. Nakano, "Experimental study on effect of load on iron loss of an electrical steel sheet under PWM inverter excitation", IEEE Trans. Magn., vol. 50, no. 11, p. 0-3, 2014.

[4] D. Zhang, H. Dai, H. Zhao, e T. Wu, "A Fast Identification Method for Rotor Flux Density Harmonics and Resulting Rotor Iron Losses of Inverter-fed Induction Motors”, IEEE Trans. Ind. Electron., vol. 0046, no c, p. 1-1, 2017.

[5] N. Denis, Y. Wu, S. Odawara, e K. Fujisaki, "Study of the Effect of Load Torque on the Iron Losses of Permanent Magnet Motors by Finite Element Analysis", in 2017 11th International Symposium on Linear Drives for Industry Applications (LDIA), 2017.

[6] M. Dems e K. Komeza, "The Influence of Electrical Sheet on the Core Losses at No-Load and Full-Load of Small Power Induction Motors", IEEE Trans. Ind. Electron., vol. 64, no. 3, p. 2433-2442, 2017.

[7] J. P. A. Bastos e N. Sadowski, Electromagnetic Modeling by Finite Element Methods, 1st. Ed. CRC Press, 2003.

[8] C. Simão, "Estudo da eficiência energética de dispositivos eletromagnéticos e de suas alimentações", In Portuguese. $P h D$ Thesis. Department of Electrical Engineering. Federal University of Santa Catarina, 2008.

[9] C. Simão, N. Sadowski, N. J. Batistela, e J. P. A. Bastos, "Analysis of Hysteresis Losses In Iron Sheets Under Arbitrary Voltage Waveforms", Eletrônica de Potência, v. 13, p. 285-289, 2008.

[10] C. Simão, N. Sadowski, N. J. Batistela, e J. P. A. Bastos, "Evaluation of hysteresis losses in iron sheets under DCbiased inductions", IEEE Trans. Magn., vol. 45, no. 3, p. 1158-1161, 2009.

[11] A. Boglietti, A. Cavagnino, M. Lazzari, e M. Pastorelli, "Predicting iron losses in soft magnetic materials with arbitrary voltage supply: An engineering approach", IEEE Trans. Magn., vol. 39, no. 2 II, p. 981-989, 2003. 